\title{
الكتابة الصوتية
}

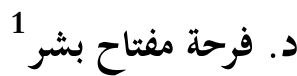 \\ كلية الآداب - جامعة سرت
}

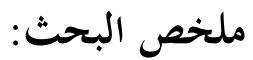

يتناول هذا البحث موضوع الكتابة الصوتية الذي حظي بالاهتمام والدراسة

من قِبَل العديد من الباحثين منذ فترة، ويتناول عددًا من المواضيع ذات العلاقة المتمثلة في ماهية لغة الفكر، وكيفية التعبير عنها، وما مدى اختلاف اللغات؟ وعلاقة ذلك بلغة الفكر، ثم ماهية نظرية الفونيم، واختلاف الآراء العلمية حوله قديمًا وحديثًا، وماهية الكتابة الصوتية، وما المقصود بالكتابة الصوتية الدولية والخاصة؟ ويُختم بالإجابة عن سؤال مهم، ألا وهو : هل يمكن وضع رموز للأصوات العربية واعتمادها رموزاً خاصةًّ 


\section{Abestract}

The current research deals with the subject of sound writing in Arabic Languge which has been studied by many researchers for a while. It discussess a number of related topics, namely the nature of the language of thought, how it is expressed, how different the languages are and how they are related to the language of thought. In addition, the meanings of international and private sound writing are discussed. At the end of this study, an attempt is made to answer an important question, which is whether it is possible to set symbols for Arabic sounds and adopt them as special symbols.

\section{1}

اللغة هي وحدات فكرية يدركها العقل البشري، وتشمل الوحدات المطلقة، والمتمثلة في الصفات التي لها صدور ذهنية، مثل الحركة، والسكون، والحياة، والموت، والشجاعة، والجُبن... إلخا، إضافة للوحدات المقيدة المتمثلة في الذوات المحسوسة التي تمتلك صور ذهنية، مثل الإنسان، والشجرة، والسمكة... وإلخ. وتلعب الجملة الفكرية دورا مهمًّا في التمييز بين الذوات وصفاتما، وتتسم هذه اللغة بالذاتية، بمعنى أن اللغة الفكرية لكل إنسان هي نتيجة محصلة ثقافته اللغوية من وحدات مطلقة ووحدات مقيدة، وتنسحب هذه الصفة على اللغات العامة، بمعنى أن لغات المجتمعات الإنسانية هي لغات خاصة بها، تعبر عن وحداتم المطلقة والمقيدة التي تؤدي أغراضهم هم. وبما أن لغة الفكر هي وحدات فكرية، منها ما هو مطلق، ومنها ما هو مقيد، فإن الإنسان هو بحاجة إلى التعبير عن هذه الوحدات، وقد مرت مرحلة التعبير عن لغة 
الفكر بمراحل، فكانت البداية باستخدام الإشارات للتعبير عن تلك الوحدات إلهامًا أو محاكاة(1)، ثم انتقل العقل البشري بعد ذلك إلى مرحلة التعبير عن لغة الفكر بالصور، والنقش، والنحت(2) وقد خلقت هذه المرحلة العديد من الآثار التي تُعد اليوم دلائل على حضارات أمم انتهت منذ زمن، وإشارة إلى معالم لغات غدت ميتة اليوم، ثم جاءت بعد ذلك مرحلة التعبير بالكتابة، واستخدام الحرف ليدل على الوحدات الفكرية المطلقة والمقيدة التي رسخت في ذهن الفرد، بمعنى أن الإنسان قد وصل إلى مرحلة يرمز إلى تلك الوحدات بأصوات يصدرها هو؛ ليكون فيما بعد وسيلة للتواصل الإنساني داخل جماعة معينة، سواءً بقصد، أو بدون قصد؛ ولذلك فإن اللغة هي "أصوات يُعبر بها كل قوم عن

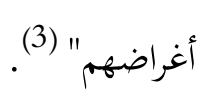

إن دراسة الكتابة الصوتية موضوع يُّح على الذهن منذ فترةٍ لما تلقته هذه الظاهرة من أهمية، ومن بحث وتحليل في جوانبها المختلفة، ولربما هذا السبب الذي دعاني للكتابة فيها من خلال طرح عدة مواضيع، أرى أها هي أساس الخوض في موضوع الكتابة الصوتية، ومن هذه الدراسة تدخل في إطار المنهج الوصفي لهذه الظاهرة والتاريخي من خلال التتبع العلمي للأطوار التي مرت بها الظاهرة.

ويتناول البحث في هذا البحث عددًا من المواضيع، متمثلة في ماهية لغة الفكر، وكيفية التعبير عنها، وما مدى اختلاف اللغات؟ وعلاقة ذلك بلغة الفكر، ثم ماهية نظرية الفونيم، واختلاف الآراء العلمية حوله قديمًا وحديثًا، وماهية الكتابة الصوتية، وما

$$
\begin{aligned}
& \text { (1) ينظر: الدراسات اللهجية عند ابن جني، 269-275. } \\
& \text { (2) ينظر: تاريخ اللغات السامية، ص25. }
\end{aligned}
$$

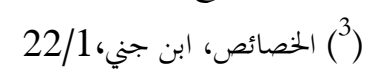


المقصود بالكتابة الصوتية الدولية والخاصة، وأختم بالإجابة عن سؤال مهم، ألا وهو: هل يمكن وضع رموز للأصوات العربية، واعتمادها كرموز خاصة؟ وتكمن أهمية هذا البحث في كونه دراسة وصفية لظاهرة الكتابة الصوتية، التي أصبحت مطلبا ضروري في مستويات التحليل اللغوي الحديث، إضافة إلى أنه محاولة لفتح باب الحوار من أجل إمكانية اعتماد رموز صوتية خاصة بلغتنا العربية، تتمشى وقواعدها، وتحافظ على حليها، وجمالها، وتمكنا من إيصال معانيها للآخر.

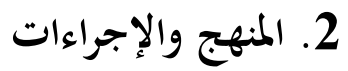

فرضت طبيعة البحث استخدام المنهج الوصفي، وذلك من خلال استعراض بعض القضايا اللغوية ذات العلاقة المباشرة بالكتابة الصوتية، إضافة للمنهج التاريخي والمتجسد في التتبع التاريخي لنشأة العلاقة بين اللغة والفكر، وترجمتها لأصوات لغوية، إضافة لتتبع مراحل الاهتمام العامي والعربي بنشأة الكتابة الصوتية.

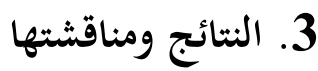

\section{1 اختلاف اللغات وعلاقته بلغة الفكر:}

يعود اختلاف لغات البشر إلى اختلاف لغة فكر كل إنسان عن الآخر، وبالتالي اختلاف لغات المجتمعات الإنسانية، كلٌّ بحسب موقعه الجغرافي، والزمني، والظروف الاجتماعية، والاقتصادية، والدينية، والتاريخية، والسياسية التي يعيشها. 
عليه، فإنه لا يمكن أبلًا عقد مقارنة بين كلمة (cat) و (قطة)، والسبب هو اختصاص كل مجتمع أو أمة بأصوات معينة، تستخدم للدلالة على الوحدات المطلقة والوحدات المقيدة(1)، إضافة إلى وجود تباين في استخدام الأصوات داخل اللغة الواحدة، ومن ذلك أن صوت (السين) في قوله- تعالى-: (البقرة، الآية: 45) غير استخدام (السين) في قوله- تعالى - : (الغاشية الآية: 22)، حيث تحولت الثانية إلى الصاد على وَفْق قانون المماثلة الصوتية، إضافة إلى وجود صور الرمز في اللفظ، وانعدامها في الصوت، والعكس، كما في (أل) الشمسية، والقمرية، وهمة الوصل، كما في (الكتاب) و(الناس) و(اذهب).

وهذا الاختلاف من حيث نوعية الأصوات المستخدمة في كل أمة أو مجتمع، يؤدي إلى اختلاف دلالات تلك الأصوات، ومن ثيَّ الألفاظ، وهذا ما أدى إلى اختلاف

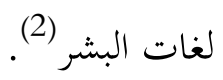

والخلاصة: أن كل ججتمع يختار أصوات دالة على احتياجاته، فأحيانًا تضاف أصوات قديمة، وأحيانًا أصوات جديدة، وأحيانًا يتم استبدالها بأصواتٍ أخرى، وأحيانًا تنحرف مخارج الأصوات عن موضعها الأساسي، وقد يمر صوت بأكثر من تغير واحد، إلا أن الرسم أو الخط يبقى كما هو في النطق، على أنه الخط الجامد الذي لا يتغير، وهذا ما حدث مثلاً مع القاف في العربية.

$$
\begin{aligned}
& \text { ( ) الكتابة الصوتية، د. حسام سعيد النعيمي، ص6. }
\end{aligned}
$$

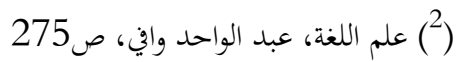


ويدخل في هذا الاختلاف قضية الاختلاف في رسم الصوائت أيضًا، والتي تلعب دورًا مهمَّما جدّا في اختلاف اللغات بين الأمم، وبالتالي فإن لغات المجتمعات هي لغات تُعبر عن احتياجاهم، حتى وإن اختلفت تلك الأصوات مع اللغة الأدبية الموجودة، أو المثالية التي ارتضاها جمهور العرب لأدجم؛ ولذلك قال ابن جني: "اختلاف اللغات وحكمها حجة" (1)

وينسحب هذا على الصوائت أيضًا، انظر في هذه الجملة، وتمعن ذهب سالم إلى الجامعة

فحين كتابتها بالضبط القديم لوضعت رموز الصوائت القصيرة، كأن يكون رمز

الفتحة (ا)، والكسرة (يـ)، والضمة (و ) وتكتب هكذا

(ذا هابا ساليمون إيلاى الجاميعاة)

3. 2 ظاهرة التحريف والتصحيف:

ومن ظواهر الاختلاف بين اللغات، ظاهرة التحريف والتصحيف التي يعود سبب انتشارها إلى إغفال الإعجام قديمًا، وأما حديثًا، فيتمثل في ذلك الكم الهائل من الأخطاء المطبعية أثناء النقل عن القدماء، إضافة إلى الاختلاف في القيمة الصوتية، والصرفية للصوت الواحد، نحو قولك:

(وعد، ويقول، ويد، وليس)

12/2 ( الخصائص، ابن جني، (12) 
والاختلاف هنا اختلاف بين الصامت والصائت، فالواو في (وعد) هي صوت احتكاكي، في حين أها في (يقول) جاءت صائتًا طويلاً (صوت مد)، وكذلك الحال في الياء في (يد) و(ليس).

إلا أن هذا الاختلاف لا يؤثر كثيرً على آلية نطق الصوت إلا في المساحة الزمنية التي يستغرقها حدوث المد، وهذا لا يحدث إلا في العربية، إضافة إلى حالة حدوث الاحتكاك من عدمه (1).

أما من حيث الرسم، فإنه لا يوجد فرق في رسم الواو الصائتة والواو الصامتة، وكذلك الياء في العربية، وإنما الاختلاف فقط في الكتابة الدولية حيث يرمز للواو الصامتة بالرمز (Wu)، والصامتة بالرمز (uu). في حين أنه في الإنجليزية يحدث فرقًا وتغيرً كبيرًا، حيث يمكن التعبير عن الواو الاحتكاكية أي الصوت الصامت برمزين (W)، و) و(One- wat) كذلك (O) وكذلك الحال مع الواو الصائتة؛ إذْ يمكن التعبير عنها برمزين (OO- W) كقولك ركرين (2) $($ food- two $)$ 3. اختلف العلماء حول مفهوم الفونيم الذي هو الصوتيمة، وهي أصغر وحدة في اللغة لا تحمل معنى، وتقوم بوظيفة التمييز بين الكلمات، ولا يمكن لها أن تتحلل إلى

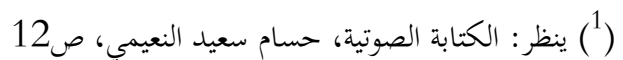

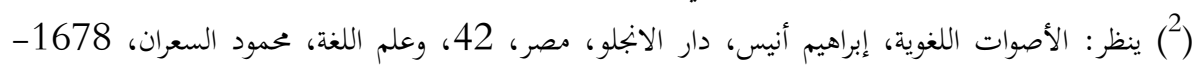

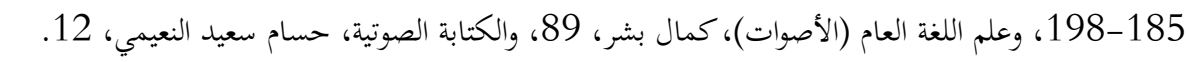
38 https://misuratau.edu.ly/journal/arts 
وحدات أصغر تقوم بالوظيفة نفسها، أي وظيفة التميز بين الوحدات التي تحمل معنى

هذه الصوتيمة تحمل أشكالاً مختلفة بحسب استعمال المجموعات اللغوية لها، وبحسب عدة عوامل تؤثر في ذلك، منها: اختلاف أعضاء النطق بين البشر، والثقافة، والسن، والنفسية، والبيئة الجغرافية إلخ (2). وهو الصورة العقلية للصوت(3) وأصل كلمة فونيم (فرنسي)، استعملها لأول مرة العالم (بودوان دي كورينتي) عام 1992م (دفريش دسكنيت) في اجتماع الجمعية اللغوية الفرنسية في أذار 1973م(4)، ثم استعمله (لوي هافي) ثم (دي سوسير) الذي ربط بين النطق والسمع، واعتبره الحصيلة النهائية للانطباعات السمعية وحركات النطق (5). وهو "الأثر المتبادل للوحدات السمعية، والوحدات المنطوقة، فهي إذن وحدة مركبة، لها جدار في السلسلة المنطوقة، وآخر في السلسلة السمعية"، ويعد أحمد مختار عمر من بين علماء العرب الذين اهتموا باستخدام الفونيم باللفظ في كتابه (دراسته الصوت اللغوي)(6)، كما ذكره كل من تمام حسان(7)، وعبد الصبور شاهين(1)، ومحمد

(198) مدخل إلى اللسانيات رضوان القضماني، مديرية الكتب والمطبوعات، جامعة البعث كلية الآداب، سوريا،

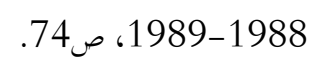

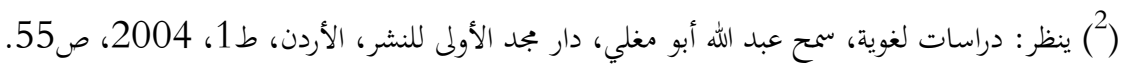

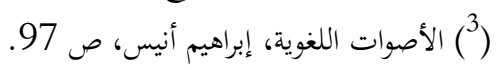

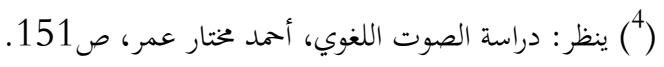
(5) ينظر: الكتابة الصوتية، حسام النعيمي، ص14. (7) ينظر: دراسة الصوت اللغوي، أمحد مختار عمر.

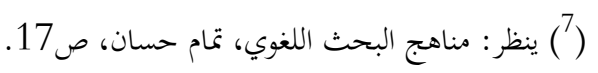
https://misuratau.edu.ly/journal/arts 
الحناش(2)، وميشال زكريا(3)، والتهامي الراجحي الهاشمي(4)، وعبد القادر القرمادي(5)

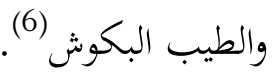

ويرى آخرون استخدام لفظة (صوتيمة) بدل الفونيم (7) كما استخدم غيرهم

لفظ (صويتة)(8)، وتنقسم الفونيمات إلى نوعين؛ الأول: الرئيسية Primary"، وهي التي تكون جزءا من أبسط صيغة لغوية ذات معنى منعزلة عن السياق، والآخر: ثانوي (Secondary)، وهي تلك الظاهرة، أو الصفة الصوتية التي تحمل معنى في الكلام

المتصل، كالنبر، والتنغيم، والمفصل (9).

3. - 2 4 الكتابة الصوتية:

تنقسم الكتابة الصوتية إلى قسمين، لاهتمامها بدراسة الأصوات اللغوية، حيث

تجعل لكل صوت لغوي رمزًا كتابيَّا خاصَّا به (10).

$$
\begin{aligned}
& \text { ( ) علم اللغة العام، عبد الصبور شاهين، ص56-58. }
\end{aligned}
$$

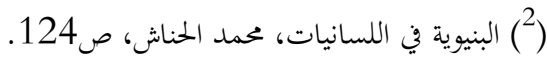

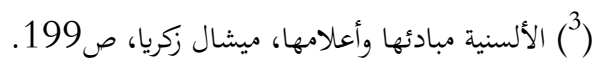

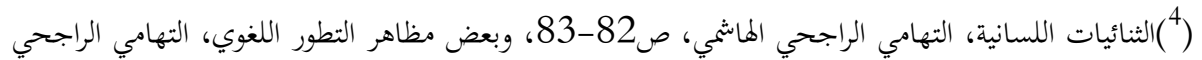

$$
\begin{aligned}
& \text { الهاشمي، ص110. }
\end{aligned}
$$

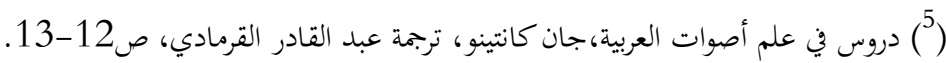

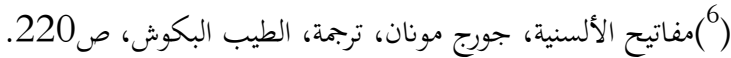

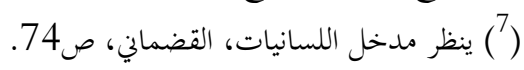

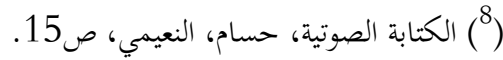

$$
\begin{aligned}
& \text { (9) ينظر: الأصوات اللغوية عند ابن سينا، عيوب النطق وعلاجه، صنام، نادر أحمد جرادات، ط1، 2009، } \\
& \text { ص125. } \\
& \text { (10) ينظر: دراسة في الصوت اللغوي، ص125. }
\end{aligned}
$$


أولما: الكتابة الصوتية الأولية، وهو نظام يمكن به التعبير عن أصوات أية لغة في العالم، تكون رموزا، تمثل إمكانيات أصوات الكام (1)، ويطلق اسم ( Phonetie Alphabet)، وتوضع رموزها بين معكوفين] [ ] والآخر: الكتابة الصوتية الخاصة، وهو نظام خاص بلغة معينة، ويطلق عليه اسم الأبجدية الصوتية (phonemie Alphahet)، وتوضع رموزها بين خطين مائلين / /. وقد ظهرت الكتابة الصوتية الدولية في القرن السادس عشر على يد اللغوي الإنجليزي (هنري سويت) (ت1912م) الذي أنشأ الجمعية الصوتية الدولية عام 1986م، وكان رئيسًا فخريَّا لها.

وتبنت هذه الجمعية الرموز التي وضعها (سويت) مستخدمًا فيها الرموز الرومانية، مع إدخال بعض التعديلات، كما تطلب التطور اللغوي ذلك، ومن المبادئ التي نادت

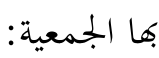
1- حين يوجد صوت واحد في عدة لغات، فلا بد أن يرمز له بنفس الرمز. 2-يجب أن تشتمل الأبجدية على أكبر قدر ممكن من رموز الألفبائية على اختلاف

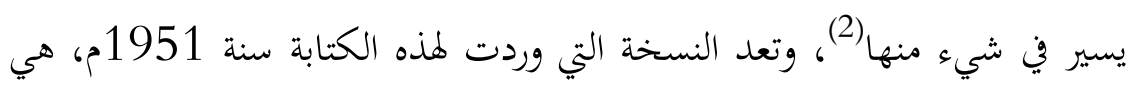

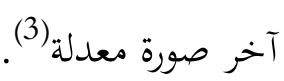

( ) ينظر: دراسة في الصوت اللغوي، أحمد مختار، ص727، والكتابة الصوتية حسام سعيد النعيمي، 15. (2) ينظر: الكتابة الصوتية، د. حسام سعيد النعيمي، ص16.

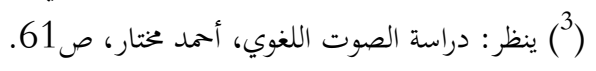
https://misuratau.edu.ly/journal/arts 
"إلا أن الجمعية خرجت على المبدأ حين وجدت الرموز الرومانية غير كافية لتمثل

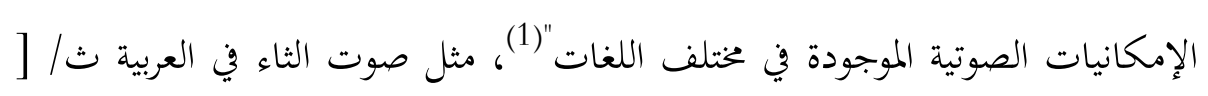

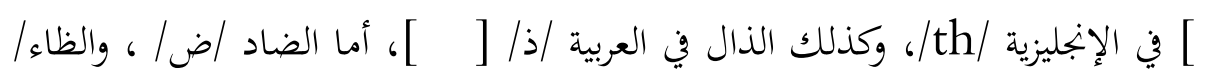
ظ|.

حيث رمزت لمما بناءً على النطق اللهجي المصري، حيث تنطق /ض/ دالا مفخمة، فرمزت لها / /، والظاء العامة للجمعية الصوتية.

وأشار (دي سوسير) إلى أن استعمال الكتابة الصوتية يجب أن يكون ضمن

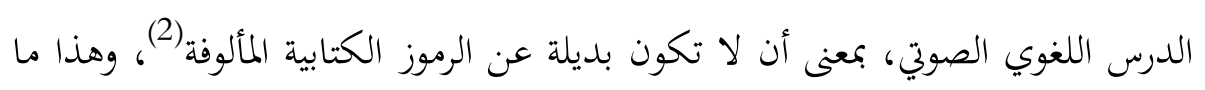

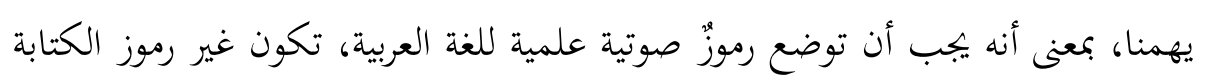
المألوفة تحت رعاية الجمعية الصوتية الدولية. ويقول (دي سوسير) في ذلك "علينا أن نرسم لكل لغة ندرسها نظامًا صوتئًا، أي

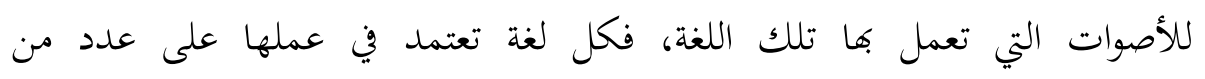

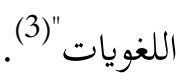

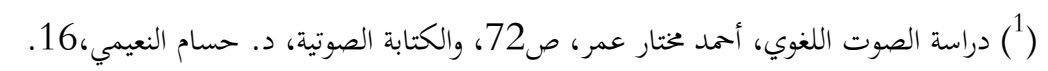

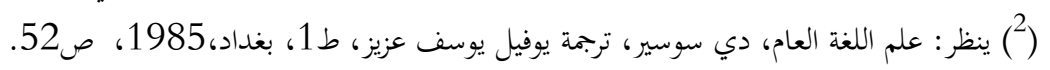

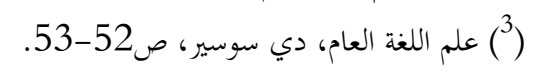
https://misuratau.edu.ly/journal/arts 
وأضاف النعيمي "أن يكون الرسم بالرموز الكتابية التي يستخدمها أهل تلك اللغة، مع الإفادة من الرموز العالمية في الرموز التنوعات الصوتية (Allo Phones) بإمالة الخطوط، أو زيادة الخطيطات، أو التنقيط، أو قلب صورة الرمز، وغير ذلك. ويمكن استخدام الصوائت القصيرة برموزها المألوفة على السطر باستخدام خطيط؛

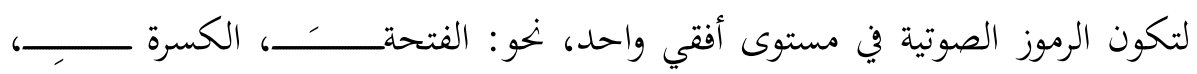

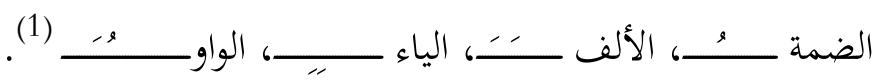

وقد ظهرت أصوات عربية كثيرة تنادي بتغيير الرموز المستخدمة في الكتابة الصوتية الحالية برموز عربية، ومن هؤلاء الدكتور عبد العزيز فهمي الذي نادى سنة 1943م في مجمع اللغة العربية بتيسير الكتابة العربية، واستبدال الحرف اللاتيني بالحرف العربي (2). ثم اقترح الدكتور تمام حسان سنة 1958م طرح الرموز العربية، والأخذ من الإغريقية واللاتينية معًا، وكتابة العربية من اليسار إلى اليمين(3). ويرى النعيمي إمكانية اشتقاق رموز عربية من الأبجديتين؛ الإغريقية واللاتينية، بحسب حاجة اللغة العربية، ثم استكمال ما يبقى من الرموز الإغريقية، وتكتب من الشمال إلى اليمين، ولعل ذلك يساعد على مواكبة التيار الفكري العالمي.

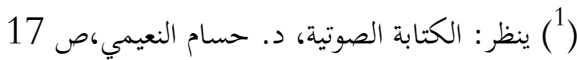

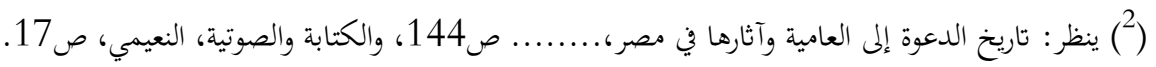

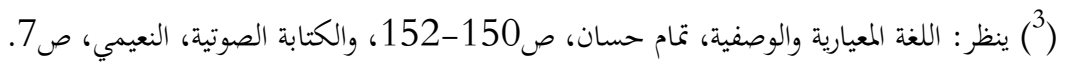


أما الألماني (براجسترسر) فهو أول من استخدم الحروف اللاتينية للتعبير عن الأصوات العربية في محاضراته التي طبعت عام 1929م، بعنوان (التطور النحوي للغة العربية)(1)

ولم يماول ذلك في الحرف العربي، ويمكنا هنا عرض بعض من الأبجدية اللاتينية التي استخدمها بزيادة بعض الإشارات المتممة التي زادها المستشرقون لتأدية الحروف

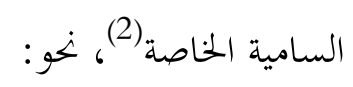

\begin{tabular}{|c|c|c|c|}
\hline $\mathrm{T}$ & التاء & $\mathrm{S}$ & الصاد \\
\hline$\check{S}$ & السين & $\mathrm{H}$ & الحاء \\
\hline$\breve{G}$ & الجيم & $\mathrm{K}$ & القاف \\
\hline $\mathrm{Y}$ & الغين & $\mathrm{D}$ & الذال \\
\hline 2 & الهمزة & $\mathrm{H}$ & الخناء \\
\hline $\mathrm{C}$ & العين & A & الألف \\
\hline đ & الضاد & $\mathrm{D}$ & الظاء \\
\hline
\end{tabular}

\section{5 تعبير الرموز وأشكال الحركات:}

تجدر الإشارة إلى أن علماء العربية كانوا قد وضعوا رموزًا للصوائت العربية قبل ألف وثلاثمائة عام(3)، إضافة إلى الصوامت، حيث رمز أبو الأسود الدؤلي (ت69هـ)

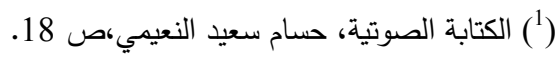

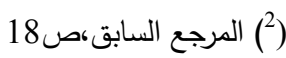
(3) (2) النظر تاريخ الحنط العربي وآدابه، محمد طاهر الكردي، ص60. https://misuratau.edu.ly/journal/arts 
إلى الحركات بالنقاط، ثم أبدلها الخليل (ت175هـ) بجرات علوية وسفلية للدلالة على الفتح والكسر، ويرأس واو للدلالة على الضم.

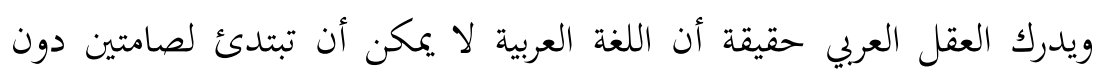

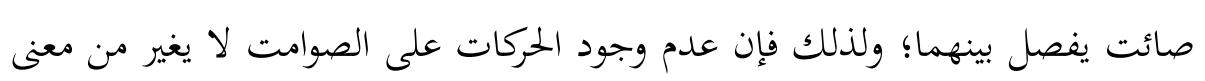

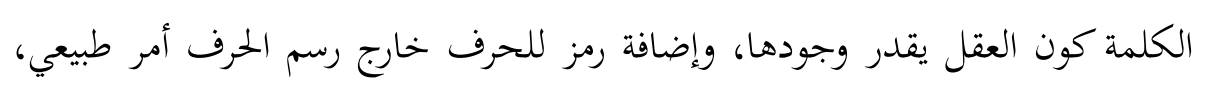
نحو وضع نقطة على الفاء ونقطتين على القاف. 3. 6 إشكالية الرموز الصوتية العربية:

يمكن القول بأن الرموز الصوتية الدولية لا تحمل من الصفة العالمية سوى الاسم،

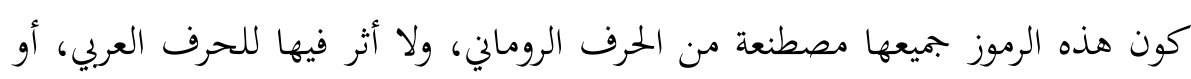

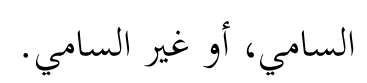

واختلفت آراء العلماء حول استخدام هذه الرموز الدولية، فمنهم المؤيد لاستخدامها في صوتي الإمالة والتفخيم، ومنهم المؤيد لاستخدامها بالحرف اللاتيني،

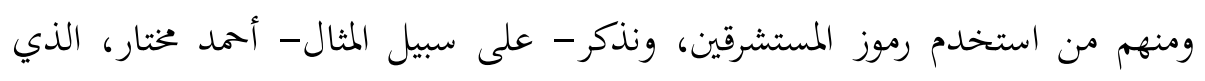
استخدم الرموز الدولية عند حديثه عن الصوتيات (فونيمات) العربية رسم الأصوات ومخارجها استخدام الرموز العربية اللاتينية(1) أما عبد الصبور شاهين، فقد استخدم رموز المستشرقين في كتابة المنهج الصوتي للبنية العربية(2)، واستخدم الراجحي الهاشمي الرمز العربي، ومع ذلك فقد استخدم النظام (1) (1) ينظر: دراسة الصوت اللغوي، أممد ختار عمر، ص275.

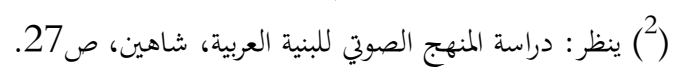
https://misuratau.edu.ly/journal/arts 
المعياري في مواضع الإمالة العربية(1)، واستخدم رمضان عبد التواب الرمز العربي، إلا أنه لجأ إلى الحركات المعيارية عند حديثه عن التفخيم والإمالة. أما داود عبده فاستخدم الرمز العربي دون أن يخلطه بغيره، وقد فرق بين رمز الياء

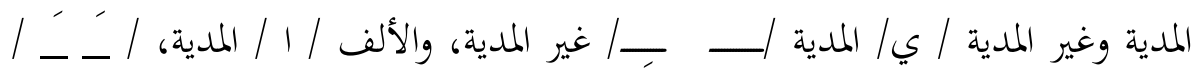

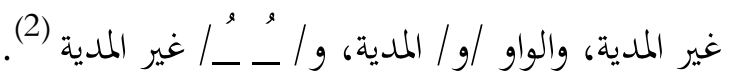
ويعد تمام حسان أكثر من استخدم الرمز اللاتيني (3)، وأورد حسام سعيد النعيمي اقتراحاً للرموز الصوتية العربية(4) موضحا بالجدول رقم (01): جدول (01) الرموز الصوتية العببية

\begin{tabular}{|c|c|c|c|c|c|}
\hline الرمز & الصوت & الرمز & الصوت & الرمز & الصوت \\
\hline |ض| & الضاد الفصيحة & $\mid \dot{r}$ & الخناء & $|s|$ & الهمزة \\
\hline$|د|$ & الضاد المصرية & |ق| & القاف & | & الهاء \\
\hline |ل/J/ & اللام المرققة & |s / & الكاف & $|\varepsilon|$ & العين \\
\hline | & اللام المفخمة & |ج| & الجيم & $|z|$ & الحاء \\
\hline |ن/ & النون المظهرة & |ش/ & الشين & $|\dot{\varepsilon}|$ & الغين \\
\hline | | | & الذال & | & الدال & $1 /$ & النون المحققة \\
\hline | & الثاء & |ت/ & التاء & |ن/ & النون المدغمة \\
\hline
\end{tabular}

( ) ينظر: بعض مظاهر التطور اللغوي، التهامي الراجحي ص102.

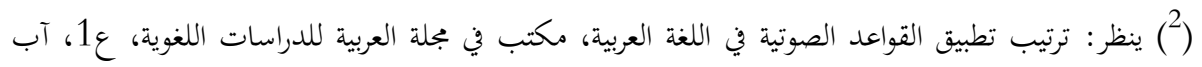

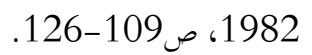

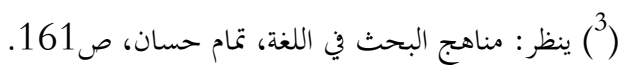

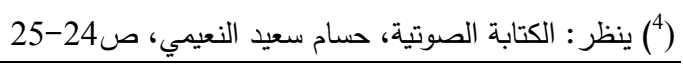
https://misuratau.edu.ly/journal/arts 


\begin{tabular}{|c|c|c|c|c|c|}
\hline |ف| & الفاء & |ص| & الصاد & $|s|$ & الراء المرتفعة \\
\hline | & الميم & $|j|$ & الزاي & 11 & الراء المحققة \\
\hline | & الميم المفخمة & |س/ & السين & $|b|$ & الطاء \\
\hline I, & الياء غير المدية & |ي| & الياء المدية & |ظ| & الظاء \\
\hline 1 & الفتحة & |ت- & صوت الإمالة & | gl & الواو المدية \\
\hline \multirow[t]{2}{*}{1} & الألف والكسرة & | & صوت تفخيم & I & الواو غير المدية \\
\hline & & & & 1 & الضمة \\
\hline
\end{tabular}

ويتضمن الجدول رقم (02) الرمز العربي المقترح لاستخدام في مقابل الرموز الدولية

التي وضعها المستشرقون: - الت

جدول رقم (02) الرمز العربي في مقابل الرموز الدولية

\begin{tabular}{|c|c|c|c|}
\hline المقترح & المستشرقون & الرمز الدولي & الصوت \\
\hline$s$ & $>$ & $\partial$ & الهمزة \\
\hline ب & b & b & الباء \\
\hline ت & $t$ & $t$ & التاء \\
\hline ث & $\mathrm{t}$ & & الثاء \\
\hline ج & $\mathrm{j}$ & d & الجيم \\
\hline$\tau$ & h & h & الحلاء \\
\hline$\dot{\tau}$ & h. & $x$ & الخخاء \\
\hline د & d. & d & الدال \\
\hline ذذ & d- & d & الذال \\
\hline ر & $\mathrm{R}$ & $r$ & الراء المرققة \\
\hline ر & - & - & الراء المفخمة \\
\hline
\end{tabular}




\begin{tabular}{|c|c|c|c|}
\hline j & Z & z & الزاي \\
\hline س & $\mathrm{S}$ & $S$ & السين \\
\hline ش & $\mathrm{S}^{*}$ & $\mathrm{~S}$ & الشين \\
\hline ص & S. & S. & الصاد \\
\hline ض & - & - & الضاد القديمة \\
\hline د. & $\mathrm{d}^{*}$ & $\mathrm{~d}$ & الضاد الحديثة \\
\hline b & $\mathrm{T}$ &.$t$ & الطاء \\
\hline ظ & $\mathrm{d}=$ & Z & الظاء \\
\hline$\varepsilon$ & $<$ & $<$ & العين \\
\hline$\dot{\varepsilon}$ & $g$ & 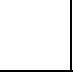 & الغين \\
\hline ف & $\mathrm{F}$ & $\mathrm{f}$ & الفاء \\
\hline ق & Q & $\mathrm{q}$ & القاف \\
\hline 5) & $\mathrm{K}$ & $\mathrm{k}$ & الكاف \\
\hline J & .1 & $\mathrm{~L}$ & اللام المرققة \\
\hline ل & 1. & $\mathrm{~L}$ & اللام المفخمة \\
\hline s & $M$ & $\mathrm{~m}$ & الميم \\
\hline ن ن & $\mathrm{n}$ & $\mathrm{n}$ & النون \\
\hline & & & غنة النون المخفية \\
\hline & & & غنة النون المدغمة \\
\hline هـ & $\mathrm{h}^{*}$ & $\mathrm{H}$ & الهاء \\
\hline 9 & & & الواو الاحتكاكية \\
\hline- & I & I & الكسرة \\
\hline 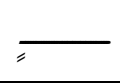 & ii & $\mathrm{i}$ & الياء المتتة \\
\hline 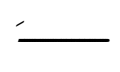 & $\mathrm{a}$ & $\mathrm{a}$ & الفتحة \\
\hline
\end{tabular}




\begin{tabular}{|c|c|c|c|}
\hline$=$ & aa & a & الألف \\
\hline - & $\mathrm{u}$ & $\mathrm{u}$ & الضمة \\
\hline 2 & $\mathrm{uu}$ & $\mathrm{u}$ & الواو الصامتة \\
\hline j & - & 3 & صوت الإمالة \\
\hline وَ & - & $\mathrm{Ou}$ & صوت التفخيم \\
\hline
\end{tabular}

5. 5. الاستنتاجات والتوصيات

1. إن لغة الفكر هي عبارة عن وحدات مطلقة، وأخرى مقيدة تعبر عنها لغات المجتمعات.

2. إن التعبير عن تلك اللغة مر بعدة مراحل حصلت خلالها أنظمة اللغات.

3. إن اختلاف لغات البشر إنما أصله اختلاف اللغات الفكرية بين البشر. 4. إن الفونيمات تلعب دورًا مهمًَّا في تحديد دلالة الكلمة. 5. الكتابة الصوتية هي نظام خاص بلغة ما، وبما أن اللغات الفكرية عند البشر تختلف، فلا بد لأنظمة الكتابة الصوتية أن تكون مختلفة تبعًا للغات الفكرية التي

$$
\text { تعبر عنها. }
$$

6. استخدام الكتابة الصوتية لا يكون إلا ضمن الدرس اللغوي الصوتي. 7. للعرب محاولات مثبتة من أجل وضع رموز صوتية خاصة بالعربية، وإن واجهته بعض العراقيل. 


\section{قائمة المراجع}

1 . الأصوات اللغوية، إبراهيم أنيس، ط5، 1979م.

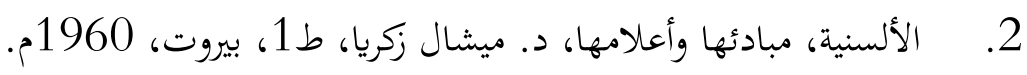

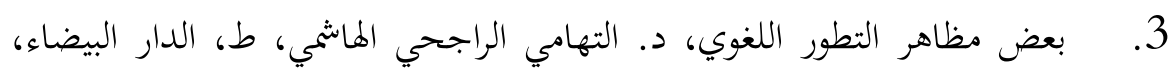

المغرب.

4. البنيوية في اللسانيات، د. محمد الحناش، ط1، الدار البيضاء، المغرب،1401هـ -

1980

5. تاريخ الخط العربي وآدابه، محمد طاهر الكردي، ط1، 1358هـ-1939م،

التجارية، مصر.

6. تاريخ اللغات السامية، اسرائيل دنفنسف، ط1، بيروت، عين ط، مصر

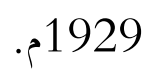

7. التطور اللغوي، مظاهرة وعلله وقوانين، د. رمضان عبد التواب، ط1، مصر،

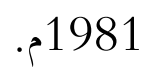

8. التطور النحوي اللغة العربية، براجسترسر، رمضان عبد التواب 1982م.

9. الثنائيات اللسانية، التهامي الراجحي، الماشمي، طبع ونشر دار النشر المغربية.

10.

1952هـ 1271

11. فقه اللغة، د. علي عبد الواحد الوافي، ط6، 1288هـ 1388-1968م.

12. 1962، 1381

13. الدراسات اللهجية عند ابن جنى، د. حسام سعيد النعيمي، درا الرشيدة، 1980

14. دراسة لصوت اللغوي، د. أحمد مختار عمر، ط1، 1396، 1976م. 
15. دروس في علم أصوات العربية، جان كانتيو، ترجمة: عبد القادر القرمادي، تونس، 1966 مرون

16. علم اللغة العام، الأصوات، د. كمال بشر، ط1 1، مصر 1973م. 17. علم اللغة العام، دي سوسير، ترجمة يونيل يوسف عزيز، ط1، بغداد، 1985، 1985م.

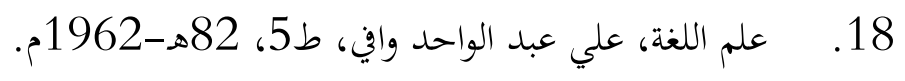

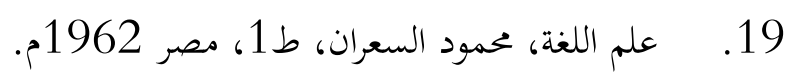

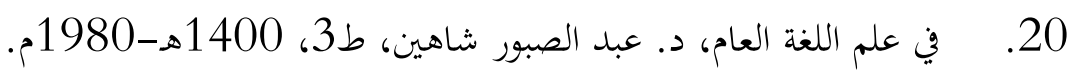
21. اللغة بين المعيارية والوصفية، تمام حسان، ط1، الديل، الدار البيضاء، المغرب،

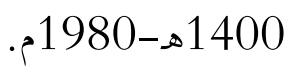
22. مناهج البحث في اللغة، تمام حسان، ط1، الدار البيضاء، المغرب، 1400هـ1980 م. 23. المنهج الصوتي للبنية العربية، عبد الصبور شاهين، ط1، بيروت، 1400هـ1980 م.

ثانيًا: الججلات العلمية الحكمة: 1. ترتيب تطبيق القواعد الصوتية في اللغة العربية، السنة الأولى، العدد الأول، 1982م، معهد الخرطوم الدولي للغة العربية.

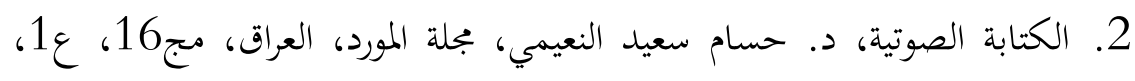
فبراير 1987م. 